\title{
From e3-value to REA: Modeling multi-party eBusiness Collaborations
}

\author{
Rainer Schuster, Thomas Motal \\ Institute of Software Technology and Interactive Systems \\ Vienna University of Technology \\ Vienna, Austria \\ \{lastname\}@ec.tuwien.ac.at
}

\begin{abstract}
In order to open-up enterprise applications to e-business and make them profitable for a communication with other enterprise applications, a business model is needed showing the business essentials of the e-commerce business case to be developed. Currently there are two major business modeling techniques - e3-value and REA (Resource-EventAgent). Whereas e3-value was designed for modeling value exchanges within an e-business network of multiple business partners, the REA ontology assumes that, in the presence of money and available prices, all multi-party collaborations may be decomposed into a set of corresponding binary collaborations. This paper is a preliminary attempt to view e3-value and REA used side-by-side to see where they can complement each other in coordinated use in the context of multiple-partner collaboration. A real life scenario from the print media domain has been taken to proof our approach.
\end{abstract}

\section{Introduction}

Integrating business processes into a Service Oriented Architecture (SOA) is certainly a hot topic. However, most current approaches are limited to the technical process aspects, disregarding the economic drivers of the information society. In former days business modeling was done by using standard process modeling methodologies such as UML's activity diagrams [1] or Petri Nets [2]. Since these methodologies have been designed for modeling a sequence of activities, modelers tend to develop their business models in a workflow-oriented way. Therefore specific business modeling techniques have been introduced in order to capture the business perspective of an e-commerce information system. Presently there are three major and well-accepted business modeling techniques - e3-value [3], Resource-Event-Agent (REA) [4] and the Business Modeling Ontology (BMO) [5].

BMO focuses on the position of a specific business partner in the e-Business network and how he can make profit. Because BMO focuses on the position of a specific business partner in the e-Business network and how that person can make profit (i.e., from an internal perspective), we take e3-value and REA as the methodology of choice for our investigation. e3-value is a methodology designed to depict a networked business idea. Within this network, business partners exchange things of economic value - both tangible and intangible. The only important thing is that the value that is being exchanged has a certain monetary value for the business partner who is requesting the value. The REA (Resource-Event-Agent) ontology is an approach for specifying the economic rationale behind business collaborations. REA captures the declarative semantics of the collaborative space between enterprises from an economic and accounting viewpoint. It describes the involved agents (A), their resources, (R) and the triggers for economic exchanges of resources by the means of economic events (E).

In order to develop a business model for an information system we propose to start with e3-value for overviewing the economic values exchanged in the network. Furthermore e3-value offers the possibility to assess the economic sustainability of the business idea by quantifying the net value flow for each actor in the value web. Whereas e3value concentrates more on the viability of the IT system, an REA business model focuses on issues that may be relevant for the implementation and alignment of an IT system. Therefore we introduce conceptual rules for mapping an e3value model to an REA model. The REA ontology assumes that, in the presence of money and available prices, all multi-party collaborations may be decomposed into a set of corresponding binary collaborations [6]. The e3-value methodology illustrates e-commerce supply chains along similar lines with its graphical modeling tool [7]. In both modeling environments, requited economic exchanges are limited to instances between just two trading partners, even in the cases where buyers and sellers are aided in their e-commerce dealings by third parties like banks, logistics providers, or taxing authorities. The difference is that e3value provides a notation in order to clearly depict the whole e-Business network constellation within its graphical modeling tool, whereas an REA model explodes geometrically in complexity as the number of trading partners grows. In order to overcome this limitation we slightly change the meta model of the REA ontology and introduce new concepts to decrease the complexity of an REA model in a multi-party 


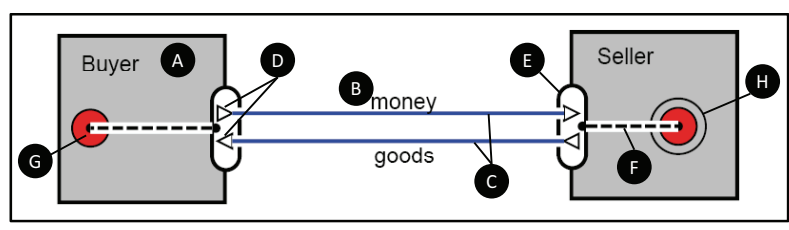

Figure 1. Simple example of an e3-value exchange

collaboration.

Our contribution within this paper is (1) to explore the different perspectives of these two modeling methodologies in the context of an example from the print media domain, (2) to define a mapping between e3-value and REA and (3) to solve the complexity problem of multi-party e-business collaborations in REA.

\section{Used business modeling methodologies}

\section{1. e3-value}

The e3-value methodology has been developed to model a value web consisting of actors who create, exchange, and consume things of economic value such as money, physical goods, services, or capabilities. It is an ontology-based methodology for modeling and designing business models for business networks incorporating concepts from requirements engineering and conceptual modeling [3]. e3-value is based on the principle of economic reciprocity meaning a "give-and-take"-approach between actors exchanging objects with an economic value - e.g. if a seller delivers goods to a buyer, he gets money in return for the goods - see figure 1.

The graphical notation of e3-value comprises a small set of concepts and relations (see figure 2) that have been introduced by Gordijn in [3]. Looking at the simple e3-value example in figure 1 actors are represented as rectangles (A). They are perceived by its environment as independent economic entities engaged in a value exchange. By exchanging value objects (B), they aim for either profitability (in case of an enterprise) or economic utility (in case of an endconsumer). Value objects do not necessarily need to be a physical good. Sometimes they represent a service, right or even a customer guarantee. A value object is always modeled in combination with a value transfer $(\mathrm{C})$ and is represented as text field. A value transfer (also called value exchange) is graphically modeled as a connection between actors.

Value objects are exchanges between actors using value ports (D). The concept of a value port is to signify whether the actor offers or requests a value object. Furthermore, it enables abstraction away from the internal business processes, and a focus on how external actors and other components of the e3-value model can be "plugged-in". Value ports are shown as small arrows pointing in the direction of the

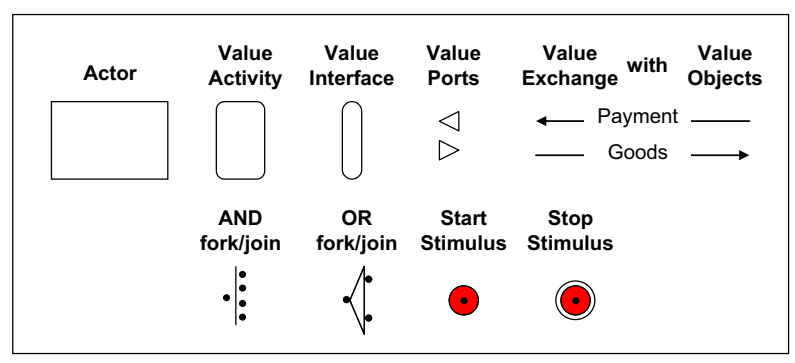

Figure 2. The notation of e3-value

value exchange. A value interface (E) groups individual value ports. Each actor may have multiple value interfaces containing value ports for offering and requesting value objects. Value interfaces bundle the value objects an actor is willing to exchange in return for other value objects. The exchange of value objects via a value interface is atomic in order to denote reciprocity - i.e., either all exchanges occur as specified by the value interface or none at all. Due to space limitations, concepts such as the e3-value scenario path $(F, G)$ are not explained in more details. We refer the interested reader to [3].

\subsection{Ressource-Event-Agent (REA)}

The REA (Resource-Event-Agent) ontology was invented by McCarthy [4] and extended to an ontology by Geerts and McCarthy [8]. The concepts of REA reflect business accounting where the needs of managing businesses through a technique called double-entry bookkeeping was formerly the standard of use. REA replaces double-entry with semantic models of economic exchanges and conversions. The acronym REA comes from the core concepts Resource, Event, and Agent. The intuition behind these core concepts is that every business transaction can be seen as an event where exactly two agents exchange resources. These basic REA concepts are illustrated in the cutout of the simplified REA meta model using a UML class diagram.

Figure 3 illustrates the simple Resource-Event-Agent structure at the MOF M2 level from a conceptual point of view. Due to space limitations the REA meta model is not depicted in its full version. Concepts such as commitments and agreements have been omitted, since they are not relevant for a mapping between e3-value and REA. Note that all REA concepts are based on UML classes at the MOF M1 level.

A business transaction or exchange has two REA constellations joined together, noting that the two parties involved in a simple market transfer expect to receive something of value in return when they trade. For example, a seller, who delivers a product to a buyer, expects a requiting cash payment in return. In other words, in order to get a resource an agent has to give up a compensating resource. 


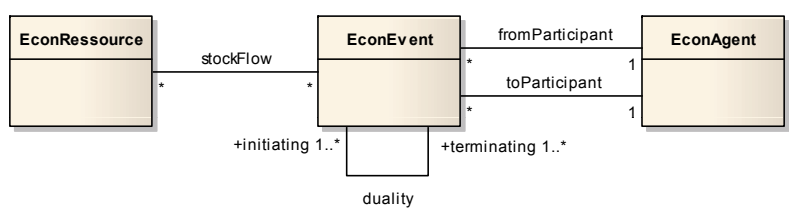

Figure 3. The base of the conceptual REA meta-model

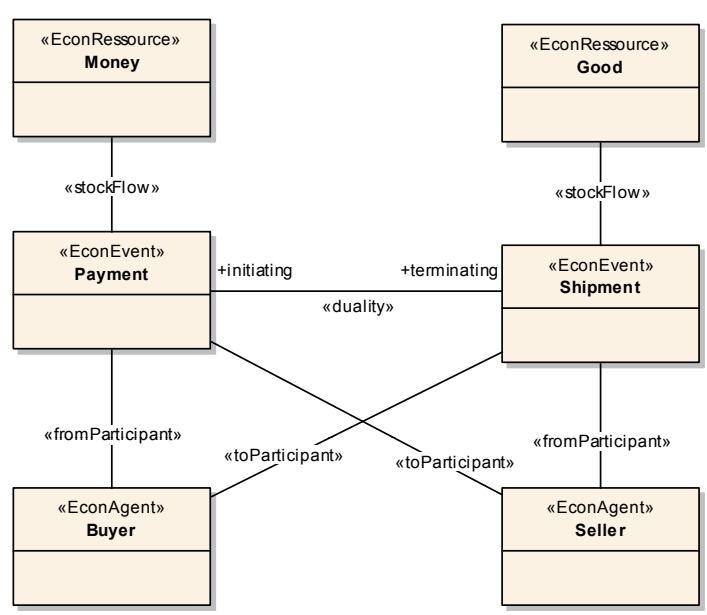

Figure 4. Simplified REA example of a buyer-seller scenario

Figure 4 depicts a simple REA scenario covering the four fundamental questions of a business collaboration:

- Who is involved in the collaboration (Economic Agents - Buyer, Seller)?

- What is being exchanged in the collaboration (Economic Resources - Money, Good)?

- When (and under what trading conditions) do the components of the exchange occur (Economic Events Payment, Shipment)?

- Why are the trading partners engaged in the collaboration (duality relationships between resource flows)?

As stated in the previous paragraphs, REA was initially designed for accounting models. However, the REA concept has found its place in some standard specifications as well. The ISO Open-edi specification [9] uses REA as an ontological framework for specifying the concepts and relationships involved in business transactions and scenarios in the Openedi sense of those terms. Furthermore the REA ontology definitions are part of the work of UN/CEFACT (United Nations Center for Trade Facilitation and Electronic Business) which is an international e-business standardization body known for its work in the area of electronic data interchange(EDI) [10].

\section{From e3-value to REA}

\subsection{A real life example from the print media domain}

The following example has been taken from the use case scenario of a national funded IT project called BSopt ${ }^{1}$ (Business Semantics on Top of Process Technology) where we applied our business modeling approach. In the print media domain customer fluctuation is mostly affected by competitors and their aggressive enticement of customers. If the competitors catch their customers with lower prices, specials or interesting advertisement gifts (produced by third-party vendors), the newspaper publisher must acquire new test readers in order to keep this customer stock. A test reader gets the same service as a reader having a permanent subscription but for a shorter time period and for a discounted fee. Additionally advertisement gifts should attract customers to become test readers (e.g. daily newspaper for 3 month and an iPod Shuffle for 29 EUR, whereas a one-year permanent subscription costs 80 EUR). The customer acquisition is either done in-house (e.g. by mail advertisement) or outsourced (in our case by a call center).

Figure 5 depicts the e3-value scenario of the acquisition of new test readers. In the following we will have a deeper look at the value transactions of our use case scenario. In e3-value a value transaction groups value transfers (the exchange of exactly one value object between two actors), which as a consequence of the value ports and value interfaces should all happen, or none at all. In figure 5, the value transaction (1) denotes that a reader pays money in order to get a permanent subscription. The value of a permanent subscription for the reader is the consumption of the newspaper service - the newspaper itself, the delivery, etc. Since these values are value objects from the reader point of view, we do not break down the value object of a permanent subscription into too multiple details. Having a look at the scenario path, the OR fork (2) denotes that the permanent reader may also get an advertising gift in order to renew his contract with the newspaper publisher (3). If he does so, the newspaper publisher must obtain an advertisement gift via the value transaction in (4). This could be traced by following the scenario path. Note, that the scenario path depicts neither any time ordering nor any process description. It helps understanding to walk through the model and determine which value transactions belong together. Looking at the test reader, he can subscribe either via traditional methods (mail, internet, face-to-face) or via telephone consultancy. This scenario is denoted by the OR fork in (5). The value transaction (6) depicts the value transfers between the test reader and the newspaper publisher in case the customer is

\footnotetext{
1. http://www.bsopt.at
} 


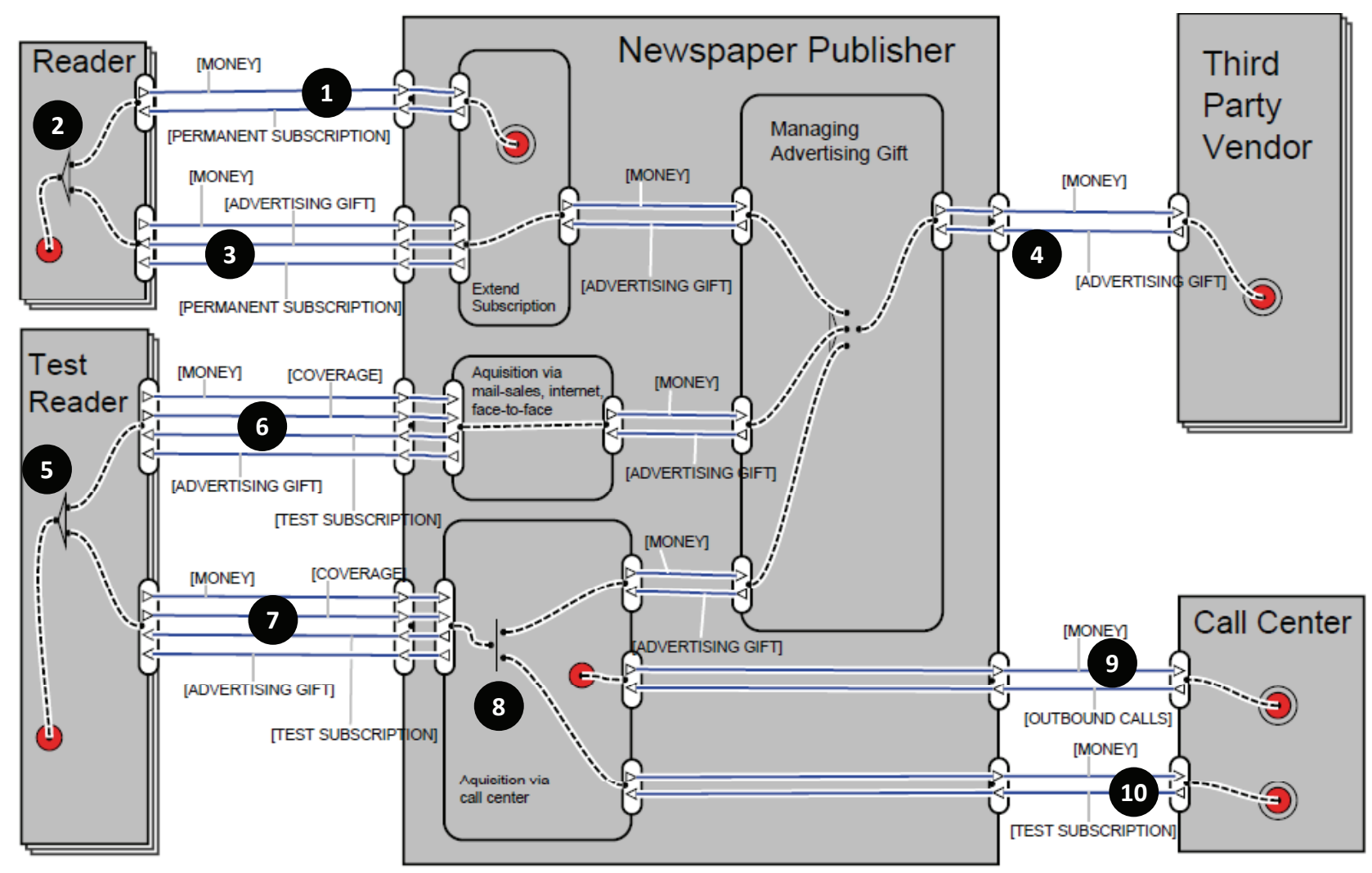

Figure 5. Acquiring Test Readers in e3-value

acquired via the in-house consultancy. The test reader gets a test subscription (the service of getting a daily newspaper for a certain period of time) and an advertisement gift (e.g. an iPod Shuffle). In return, the test reader has to pay a certain fee for consuming this service. Additionally there is an even more important value for the newspaper publisher that is exchanged between these two actors - the opportunity that the test reader turns into a permanent reader. As soon as the newspaper publisher acquires new test readers, that agent decreases the possibility that the test reader will become a reader of a competitor. In the print media domain, this indicator is called coverage. Thus, the bigger the amount of test readers the newspaper is covering, the bigger is the chance to keep the permanent customer stock. The same value transaction having the same value transfers as in (6) is depicted in (7). The difference between these two transactions is the scenario path. In order to fulfill the value transaction in (7) the value object of an advertisement gift is needed AND the test subscription brought by the call center. This is denoted by the AND fork in (8). The value transaction (9) depicts the value exchange between the newspaper publisher and the call center. For every outbound call the call center is performing, the newspaper publisher has to pay a certain price, no matter if the call center was successful or not. Thus the consuming value for the newspaper publisher is the call service by the call center in order to increase the possibility to get a test subscription. If the call center was successful the value transfer is depicted in (10). The newspaper publisher has to pay a succession fee for every test subscription the call center acquired.

\subsection{Mapping e3-value to REA}

In the following we will transform the e3-value notation into an REA-stereotyped UML class diagram. Figure 6 is a cutout of figure 5 and shows the transaction between the newspaper publisher and the call center. The figure is separated in two parts indicated by a dashed line to distinguish between the e3-value view and the REA view: The upper part shows the e3-value web and the lower part the corresponding REA class diagram. Based on the following rules we will show how to translate concepts used in e3-value to those used in REA. Below we listed the necessary transformation rules. The number beside the description follows the numeration in figure 6 .

1) An actor is an economic agent and therefore mapped to an EconAgent in the REA class diagram. The mapping is straight forward since both concepts share the same semantics. An actor in e3-value and an economic agent 


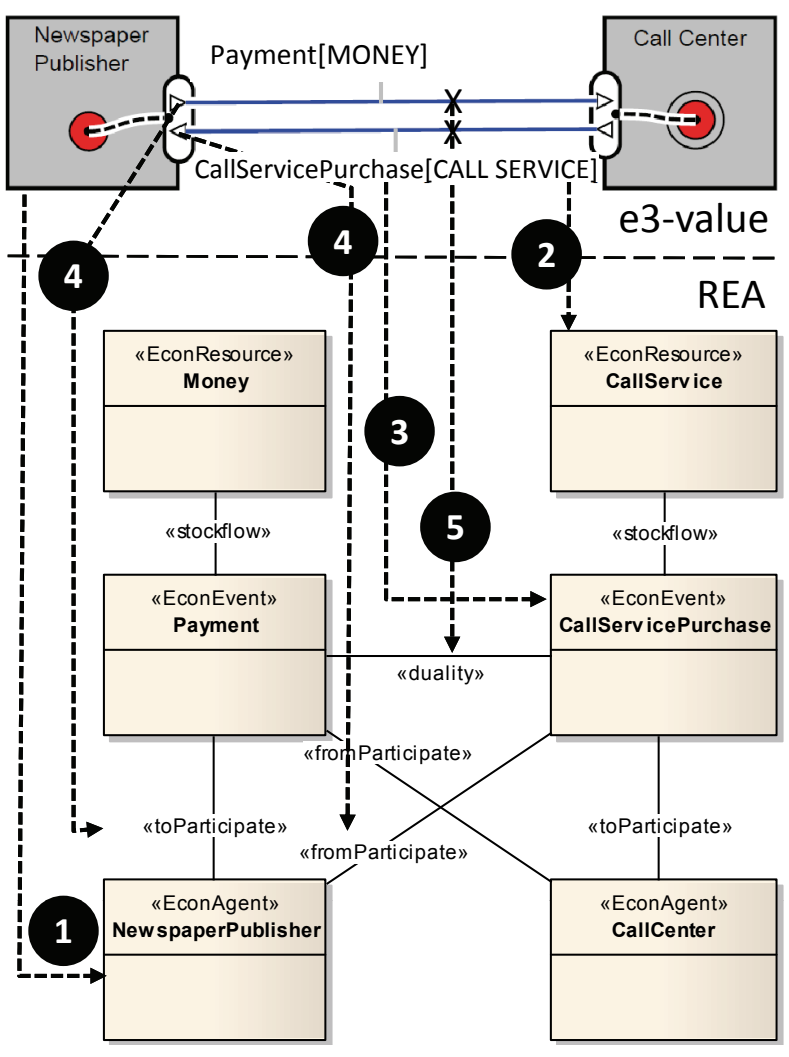

Figure 6. Mapping from e3-value to REA

in REA are both independent participants in a business transaction with the intention to gain profit.

2) A value object is an economic resource and is stereotyped as EconResource.

3) A value transfer is an economic event stereotyped as EconEvent. In figure 6 a value transfer in e3value is depicted as the line between an in-going and an out-going value port - e.g. CallServicePurchase. Since a value transfer and an economic event are used to transfer resources between participating business partners, we propose to map a value transfer to an EconEvent.

4) Value transfers in e3-value are always done between exactly two actors. This principle corresponds to the original REA notation of a ternary control relationship with two economic agents and an economic event. In our proposed mapping, this has been decomposed into its more recent ontological form with binary participate (from, to) relationships shown as fromParticipate and toParticipate associations.

5) A value transaction (paired sets of value transfers) is an economic exchange with pairs of economic events linked by duality relationships. A value transaction always follows the rule that if a value transaction takes place, all grouped value transfers happen, or none of them. The same principle is valid for economic events which are connected via a duality association. The semantic behind duality is that one event has to be fulfilled if one of its corresponding events happen.

\section{Toward multi-party collaborations in REA}

In order to get a combined view covering the REA's trading partner view and e3-value's network view we are facing various problems. In this section we discuss these problems and propose our solutions toward a consistent view of e-business models.

\subsection{Problems}

In the former section we showed that a mapping between e3-value and REA is possible since the core concepts of e3 value are direct adaptations of the original REA model. However, the main difference between both approaches is their graphical representation. The class diagram notation for REA does not satisfy the needs of an appropriate network view as it is in e3-value. A simple binary transaction in REA exchanging two resources, as portrayed in figure 6, becomes quite complex and hard to read. Extending the sample with another actor, e.g. the third party vendor who sells advertising gifts in return of money, would require at least three more classes. Additionally the corresponding associations between the different actors and the events in which they participate have to be modeled as well (four more associations for each event). Since REA explicitly considers IT implementation while e3 value ignores such considerations, it is necessary to consider representation artifacts (such as unique identifiers) directly. Therefore we need to generalize the concept of economic event in order to foster a reuse of this REA category. The following list summarizes changes needed to realize multi-party collaborations in REA:

1) Reduce the complexity of REA models regarding its graphical representation having more than three participating actors in the business network.

2) Enable the reuse of events for multiple agents.

3) Make sure that all associations between agents and events can be uniquely identified.

\subsection{Extending the REA meta-model}

In order to fulfill the needs for a combined view of REA and e3-value we introduce the concept of event realizations. With this additional concept all associations between agents and their corresponding events can be identified exactly. A similar approach is used in UMM where realizations are used to bind a business collaboration to a set of business partners [11].

To implement the concept of economic event realizations into REA we had to slightly change the original meta-model. 


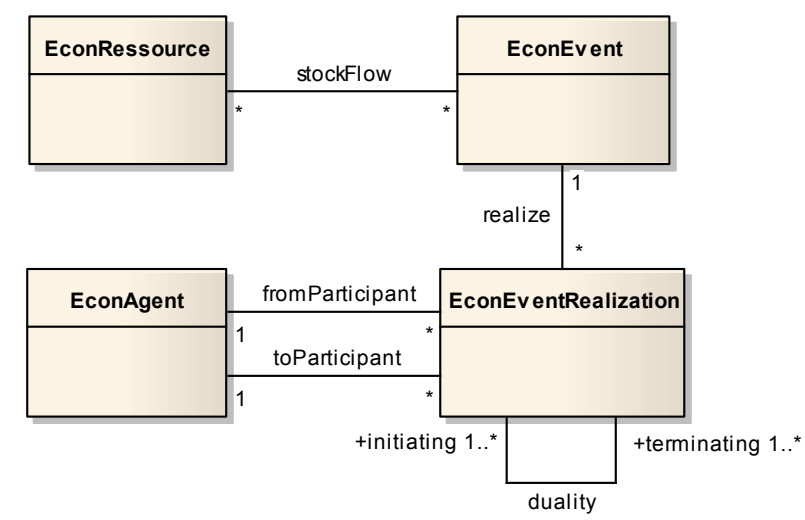

Figure 7. The extended REA meta-model

As depicted in figure 7 a new element called EconEventRealization has been added to the REA meta-model. A realization can be seen as a concrete instance of an economic event. The dependency between an event and it's realizations is modeled with a realize dependency. As a consequence economic agents are no longer associated with economic events in order to participate in an economic transaction. Instead they have to be connected with economic event realizations via fromParticipate and toParticipate relationships. The duality concept of REA stays the same with the difference that they are now modeled between economic event realizations. This means that in order to fulfill an economic event realization all corresponding realizations have to be fulfilled as well.

In order to translate e3-value models to our extended meta-model we also have to alter the mapping (section 3.2). Figure 8 depicts the transformation of the print-media use case example (see section 3.1). Due to space limitations, we only describe the exchange between the news paper publisher and the call center. The scenario is highlighted by a dashed square in figure 8 . The necessary changes are listed below and the numbers correspond with the numbers annotated in figure 8 :

1) A value transfer is mapped to EconEventRealization elements. In order to make the translation more symmetrical and easier to read, we have prefixed economic event realizations with their participating agents in their class names (e.g. NP_CC_CallServicePurchase, NP_CC_CallServicePayment). Whereas NP stands for newspaper publisher and $\mathrm{CC}$ for call center.

2) Since involved economic agents do not longer participate in economic events they are connected with their corresponding EconEventRealizations via participate associations (from, to).

3) The dependency between EconEvents and EconEventRealizations is indicated by realize connections.

4) A duality relation connects two or more EconEventRealizations. The semantic behind the duality connection stays the same (see section 3.2).

\section{Related work}

In the last decade, a lot of progress has been achieved in the domain of business modeling. Beside REA [4] and e3value [3], one of the most popular approaches is the Business Model Ontology (BMO) introduced by Osterwalder [5].

Another survey investigating the differences between the different business modeling ontologies (e.g. e3-Value and $\mathrm{BMO}$ )and their economic drivers toward service-oriented architecture (SOA) was introduced by [12]. They classify their outcome by using the Open-edi reference model standardized by ISO [9].

The DEMO framework [13], which implements the Language Action Perspective (LAP) framework [14], aims at representing the essential structure of business processes within an organization. Another promising approach which has recently been introduced by the Object Management Group (OMG) is the Business Motivation Model (BMM) [15]. The BMM specification aims at supporting the development of business plans in a structured way including the identification of necessary elements and their relationships as well as motivational aspects.

\section{Conclusion}

This paper provides different perspectives of two major business modeling methodologies - e3-value and the REA ontology in the context of a real life example taken from the print media domain. Furthermore we proposed to start with e3-value to depict the business idea of an e-business network and the value exchanges between the business partners in order to calculate the economic sustainability of the system. Afterward we proposed to translate the e3-value notation into an REA-stereotyped UML class diagram by using our mapping rules in order to specify the economic drivers of the information system from a more IT driven perspective (e.g. in regard to the implementation of the IT system with an OO platform or with a relational database). Since there is no specific REA for multi-party collaborations, teir representation explode geometrically in complexity as the number of trading partners grows. This implementation vision causes some of the extra complexity mentioned above, and ways to simplify, modify, and counteract this bias should be explored.

\section{References}

[1] Unified Modeling Language, OMG, February 2009, technical Specification V2.2, http://www.omg.org/spec/UML/2.2/Infrastructure/PDF/.

[2] K. van Hee., "Informations Systems Engineering - A formal approach," Cambridge University Press, 1994. 


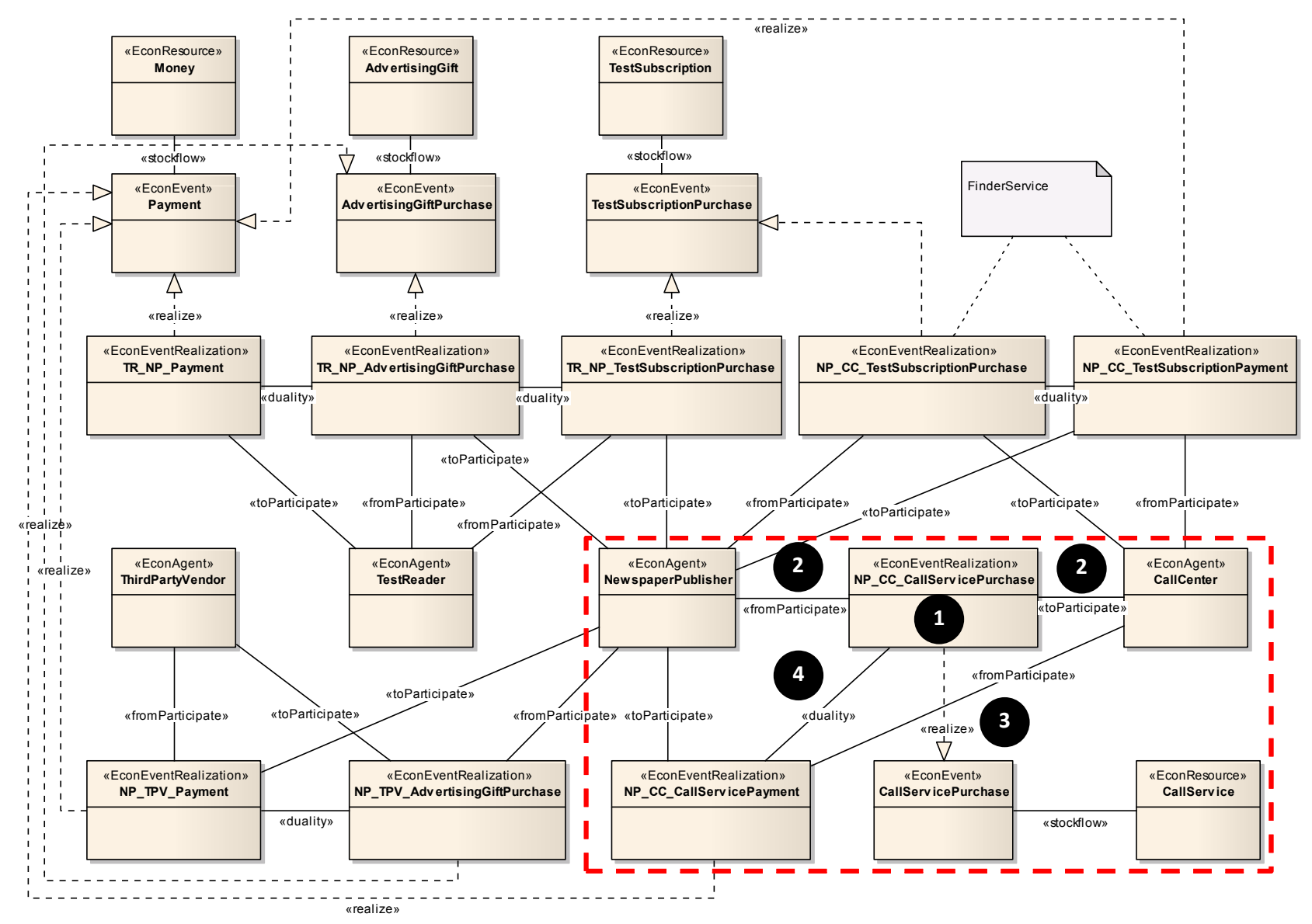

Figure 8. Mapping the e3-value sample to REA

[3] J. Gordijn and H. Akkermans, "Value based requirements engineering: Exploring innovative e-commerce idea," $R e$ quirements Engineering Journal, vol. 8, no. 2, pp. 114-134, 2003.

[4] W. McCarthy, "The REA accounting model: A generalized framework for accounting systems in a shared data environment," Accounting Review, 1982.

[5] A. Osterwalder and Y. Pigneur, "An e-Business Model Ontology for Modeling e-Business," in 15th Bled Electronic Commerce Conf., 2002.

[6] W. E. McCarthy, "On the partial mapping of mediated REA scenarios in e-commerce collaboration space," 2003, Working Paper - University of Kansas, XBRL Symposium II.

[7] J. Gordijn, "The e3-value toolset," www.e3value.com.

[8] G. L. Geerts and W. E. McCarthy, "An accounting object infrastructure for knowledge-based enterprise models," IEEE Intelligent Systems, vol. 14, no. 4, pp. 89-94, 1999.

[9] Information technology - Business Operational View Part 4: Business transaction scenarios - Accounting and economic ontology, ISO, 2007, ISO/IEC 2007, ISO 15944-4, http://standards.iso.org/ittf/PubliclyAvailableStandards/index.html.
[10] UN/CEFACT's Modeling Methodology (UMM), UMM Meta Model 2.0, UN/CEFACT, 2008, public Draft V2.0.

[11] C. Huemer, P. Liegl, T. Motal, R. Schuster, and M. Zapletal, "The development process of the un/cefact modeling methodology," in ICEC '08: Proceedings of the 10th international conference on Electronic commerce. New York, NY, USA: ACM, 2008, pp. 1-10.

[12] J. Dorn, C. Grün, H. Werthner, and M. Zapletal, "From business to software: a B2B survey," Information Systems and E-Business Management, vol. 7, no. 2, pp. 123-142, 2009.

[13] J. L. G. Dietz, "Demo: Towards a discipline of organisation engineering," European Journal of Operational Research, vol. 128, no. 2, pp. 351-363, January 2001.

[14] P. J. Denning and R. Dunham, "Innovation as language action," Commun. ACM, vol. 49, no. 5, pp. 47-52, 2006.

[15] Business Motivation Model (BMM) Specification, OMG, Sep. 2007, technical Specification V1.0, http://www.omg.org/cgibin/apps/doc?dtc/07-08-03.pdf. 